\title{
DIENES E A MATEMÁTICA VIVA: ENSINO E APRENDIZAGEM POR MEIO DE JOGOS ESTRUTURADOS
}

\section{DIENES AND THE LIVING MATHEMATICS: TEACHING AND LEARNING THROUGH THE USE OF STRUCTURED GAMES}

\author{
NOVAES, Barbara Winiarski Diesel \\ barbaradiesel@yahoo.com.br \\ UTFPR - Universidade Tecnológica do Paraná \\ FRANÇA, Denise Medina De Almeida \\ denisemedinafrança@gmail.com \\ USS - Universidade Severino Sombra
}

\begin{abstract}
RESUMO: O presente artigo tem por objetivo verificar apropriações das experiências de Zoltan Paul Dienes em revistas pedagógicas para o ensino primário ao tempo do movimento da matemática moderna. Traremos como referencial os estudos da história da educação e da história cultural. Concluímos que nos artigos analisados, há ênfase para a maneira de ensinar de acordo com as fases de desenvolvimento cognitivo, da utilização de jogos com materiais estruturados e da metodologia mais adequada para cada uma delas. O estudo também revela o pioneirismo de um grupo de professores do Rio Grande do Sul na apropriação e circulação das ideias de Dienes e experimentação em classes piloto das séries inicias.
\end{abstract}

PALAVRAS-CHAVE: História da Educação Matemática. Revistas Pedagógicas. Séries Iniciais. Zoltan Dienes.

ABSTRACT: This article has as objective to verify appropriations regarding Zoltan Paul Dienes experiences in pedagogical magazines for the primary teaching during the new math movement. The references are the studies of education history and cultural history. We conclude that in the analyzed articles, there are emphasis in teaching according with the phases of cognitive development, in the use of games with structured materials and in the use of a proper methodology for each one of those. The study also reveals the pioneering of a teachers group in Rio Grande do Sul state (Brazil), concerning the appropriation and circulation of Dienes ideas and the corresponding experimentation in primary school initial classes.

KEYWORDS: Mathematics Education History, Pedagogical Magazines, primary school initial classes, Zoltan Dienes.

\section{INTRODUÇÃO}

"Conheça a incrível escola totalmente baseada em jogos", esse era o título do artigo que circulava na internet no mês janeiro de 2016. O texto do jornalista Paulo Fernando Silvestre Jr. discorre sobre uma escola considerada inovadora, a "Quest to 


\section{Atos de Pesquisa em Educação - ISSN 1809-0354 \\ Blumenau, v. 12, n.2, p.425-445, mai./ago. 2017 \\ DOI: http://dx.doi.org/10.7867/1809-0354.2017v12n2p425-445}

Learn ${ }^{1 "}$, localizada em Nova lorque, Estados Unidos e que atende alunos de seis a doze anos. Segundo Silvestre Jr (2015), a escola possui resultados acadêmicos impressionantes, baixo índice de faltas e evasão escolar, além disso, os professores adoram trabalhar no local e os pais apoiam fortemente. Os livros são substituídos por games e jogos de tabuleiro. Professores, alunos e funcionários fazem parte de um processo de colaboração mútua em que todos ensinam e aprendem. Ainda, utilizam "aprendizado baseado em problemas, uso criativo de tecnologias e espaços físicos flexíveis" (SILVESTRE JR, 2015).

Apesar do caráter não científico da notícia, desencadeou várias reflexões e questionamentos sobre as pesquisas que desenvolvemos no âmbito da história da educação matemática. Será que educadores do passado já tinham pensado de alguma maneira em utilizar jogos como recurso metodológico para ensinar matemática na escola primária?

Com o cuidado de não cometer anacronismos, em olhar para o passado com os olhos do presente, podemos dizer que a utilização de "materiais manipulativos", "jogos"”, "jogos com materiais estruturados" já estava muito presente em tempos passados e também eram considerados inovações. Como ocorreu este processo de utilização dos jogos estruturados em tempos passados? O que permanece em nossas práticas e o que é descartado?

Compreendendo que a história da educação matemática é um conhecimento necessário para a formação do futuro licenciado, seja em matemática, seja em pedagogia e que o conhecimento sobre o passado pode fazer com que pensemos práticas do presente de forma mais crítica e fundamentada, o presente artigo $^{4}$ tem

\footnotetext{
${ }^{1}$ Para saber mais sobre a escola: http://www.q2l.org/. Acessado em: 05 de março de 2016.

2 Termo do latim "jocus" que significa gracejo, brincadeira, divertimento. Uma atividade física ou intelectual que integra um sistema de regras e define um indivíduo (ou um grupo) vencedor e outro perdedor. Disponível em: http://www.significados.com.br/jogol. Acesso em 08 de mar. 2016.

${ }^{3}$ Os elementos do conjunto de objetos possuem propriedade definidas. É especialmente concebido para favorecer a aquisição de determinados conceitos matemáticos.

${ }^{4}$ Uma versão preliminar deste artigo foi apresentada no XVIII Endipe em agosto de 2016 na mesa "Aspectos didáticos metodológicos na configuração dos saberes matemáticos para formação do professor primário (1920 a 1980)".
} 


\section{Atos de Pesquisa em Educação - ISSN 1809-0354 \\ Blumenau, v. 12, n.2, p.425-445, mai./ago. 2017 \\ DOI: http://dx.doi.org/10.7867/1809-0354.2017v12n2p425-445}

por objetivo verificar apropriações das experiências de Zoltan Paul Dienes ${ }^{5}$ em revistas pedagógicas para o ensino primário ao tempo do movimento da matemática moderna ${ }^{6}$ (MMM).

Foram utilizados, como fonte privilegiada, quatro artigos publicados na Revista de Ensino do Rio Grande do Sul $^{7}$, nos anos de 1972 e 1973 que relatam ações do Grupo de Estudos sobre o Ensino da Matemática de Porto Alegre (GEEMPA) quando da visita do prof. Zoltan Paul Dienes (POÇAS E ATHANÁSIO, 1972) e seus desdobramentos por meio de experiências em classes-piloto ${ }^{9}$ (GROSSI ${ }^{10}$, 1973) organizadas pelo grupo citado que utilizaram a metodologia proposta por ele. Além de grupos de estudos, novas maneiras de trabalhar com as operações matemáticas para o primeiro ano (FAGUNDES ${ }^{11}$, 1972) e estudo das estruturas de grupo (LOPES $\left.{ }^{12}, 1973\right)$.

\footnotetext{
${ }^{5}$ Zoltan Paul Dienes - Matemático húngaro, nascido em 1916, obtém o título de Doutor em Matemática e Psicologia, pela Universidade de Londres, em 1939. Trabalha como professor em Highgate School e Dartington Hall School e nas Universidades de Southampton, Sheffield, Manchester e Leicester, todas na Inglaterra. Torna-se pesquisador do Centro de Estudos Cognitivos da Universidade de Harvard (1960-1961) e professor adjunto em Psicologia na Universidade de Adelaide (Austrália), no período de 1961 a 1964. É nomeado diretor do Centro de Investigação em Psicomatemática, em Sherbrooke, Quebec, em 1964 e, após o fechamento do Centro em 1975, por motivos políticos, dedica seus estudos à educação indígena, como professor na Universidade de Brandon, no Canadá, até 1978. Disponível em: <http://www.dienes.hu/page biographies DZ.html>. Acesso em 31 out. 2010. Além disso, possui várias obras traduzidas para o português, na década de 1970, ministra diversos cursos no Brasil e apoia as classes experimentais (SOARES, 2014).

${ }^{6}$ As principais características do MMM eram a defesa do Método axiomático, unidade matemática, estudo das estruturas algébricas, topológicas e de ordem, rigor na linguagem matemática, ênfase na abstração e na teoria de conjuntos (NOVAES, 2012). Para saber mais sobre o Movimento ver, dentre outros, Oliveira, Leme da Silva e Valente (2011).

${ }^{7} \mathrm{O}$ grupo de pesquisa GHEMAT disponibiliza um grande acervo digital contendo, entre outros, legislação, manuais pedagógicos, revistas pedagógicas no endereço: https://repositorio.ufsc.br/handle/123456789/1769 (acessado em 03/01/2016). Em consulta ao repositório não encontramos nenhum artigo que citasse o professor Zoltan Dienes, contudo Pereira (2010) nos forneceu quatro artigos publicados na Revista de Ensino do Rio Grande do Sul nos anos de 1972 e 1973.

${ }^{8}$ Integrante da equipe da Revista de Ensino (POÇAS, ATHANÁSIO, 1972).

${ }^{9}$ Para mais informações sobre as classes-piloto organizadas pelo GEEMPA, consultar Fischer (2006).

${ }^{10}$ Presidente do Grupo de Estudos sobre Ensino da Matemática de Porto Alegre (GEEMPA) - é professora do Laboratório de Matemática do I. E. "Gen. Flores da Cunha" - Porto Alegre, RS. (GROSSI, 1973, p.53)

${ }_{1}$ Professora de Didática da Matemática da Clínica de Aprendizagem do Laboratório de Matemática do Instituto de Educação "General Flores da Cunha" e integrante do GEEMPA-RS (FAGUNDES, 1972, p.24).

${ }^{12}$ Integrante do grupo de Ciências, Grupo - Base de Currículo de $1^{\circ}$ Grau do Departamento de Educação Fundamental da Secretaria de Educação e Cultura do Estado do Rio Grande do Sul (LOPES, 1973, p.14)
} 
Os estudos mais recentes do Grupo de Pesquisa em História da Educação Matemática no Brasil (GHEMAT), amparados nas pesquisas de Hofstetter e Schneuwly (2009, p.19) diferenciam os saberes a ensinar como objeto da docência e os saberes para ensinar como ferramenta profissional do professor. Em relação ao presente artigo entendemos que as experiências de Dienes mobilizam um saber para ensinar relacionado a prática docente (os modos de aprendizado os alunos, os modos de tratar o saber a ensinar, etc).

Diante do exposto, procuraremos responder a seguinte questão norteadora: $O$ que revelam as revistas pedagógicas em termos das apropriações ${ }^{13}$ realizadas dos estudos de Zoltan Paul Dienes?

\section{O CENÁRIO SÓCIO-POLÍTICO}

Formou-se o cenário para mudanças com a promulgação das duas leis nacionais da educação: 4.024/1961 e 5.692/1971.

Após 13 anos de estudos e discussões, foi promulgada a Lei de Diretrizes e Bases da Educação (BRASIL, 1962). Pela primeira vez, uma legislação conseguiu fixar diretrizes gerais para a educação nacional. Ao abordar todos os níveis e com validade para todo território nacional, caminhou para a unificação dos sistemas de ensino na descentralização e flexibilização curriculares. Também inovou ao propor um planejamento educacional e a abertura de novas experiências metodológicas em classes experimentais, o que propiciou a liberdade de propostas inovadoras experimentais em vários estados brasileiros.

A aceleração no ritmo do crescimento econômico e na demanda social de educação agrava a crise do sistema educacional, justificando os vários acordos de colaboração técnica e financeira entre o Ministério da Educação e Cultura (MEC) e a

\footnotetext{
${ }^{13}$ A apropriação, a nosso ver, visa a uma história social dos usos e das interpretações, referida a suas determinações fundamentais e escrita nas práticas específicas que a produzem. Assim, voltar à atenção para as condições e os processos que, muito concretamente, sustentam as operações de produção do sentido (na relação de leitura, mas em tantos outros também) é reconhecer, contra a antiga história intelectual, que nem as inteligências nem as ideias são desencarnadas, e, contra os pensamentos do universal, que as categorias dadas como invariantes, sejam elas filosóficas ou fenomenológicas, devem ser construídas na descontinuidade das trajetórias históricas (CHARTIER, 1991, p. 180)
} 


\section{Atos de Pesquisa em Educação - ISSN 1809-0354 \\ Blumenau, v. 12, n.2, p.425-445, mai./ago. 2017 \\ DOI: http://dx.doi.org/10.7867/1809-0354.2017v12n2p425-445}

Agency for International Development (AID). Tais acordos ficaram conhecidos como MEC-USAID.

Nesse período, segundo Romanelli (1982), além das medidas centralizadoras adotadas pelo governo federal para suprir a demanda de matrículas e expansão do ensino, foram acrescidas outras, que visavam à estruturação do ensino, para atender às orientações dos pactos MEC-USAID ${ }^{14}$.

A tendência tecnicista implantada pela Lei 5.692/1971 surge, então, com ênfase nas tecnologias do ensino, tirando o centro do processo de ensinoaprendizagem do professor e do aluno, focando-o nos objetivos instrucionais e nas técnicas de ensino, com divisão do trabalho pedagógico entre os especialistas da educação. Há preocupações com a economia de pensamento e o raciocínio rápido, demandados pela sociedade em desenvolvimento. Em grande medida, a lei corroborava com o ideário do MMM, em um período em que se encontrava em consolidação no Ensino Primário (PORTELA, 2010; OLIVEIRA, SILVA, VALENTE, 2011; FRANÇA, 2012).

$\mathrm{O}$ conjunto de ideias propagado pelo MMM adequava-se à política econômica adotada pelo país e à concepção tecnicista da nova LDB de 1971 (BRASIL, 1971). Esse fato pode ter impulsionado o privilégio na divulgação das ideias de Dienes nas Revistas Pedagógicas destinadas a professores primários nesse período.

\section{PRINCIPAIS IDEIAS}

O GEEM ${ }^{15}$ - Grupo de Estudos do Ensino de Matemática - publicou e distribuiu o texto, produzido a partir da Conferência de Dienes, em Porto Alegre (1972), em que o autor reafirma suas propostas metodológicas para introduzir o conceito de número, adaptada, com ênfase nas estruturas matemáticas e aos estudos da Psicologia e Pedagogia. Nele, a sequência de atividades sugeridas, para

\footnotetext{
${ }^{14}$ São assinados 12 acordos MEC-USAID, entre 1964 e 1968, que pressionaram e exigiram racionalização e eficácia na aplicação de recursos (FRANÇA, 2012).

${ }^{15}$ Grupo fundado em 31/8/1961, tendo os professores Sangiorgi, como presidente, e George Springer, como colaborador. Os componentes do GEEM, em grande medida, tinham a facilidade de frequentar cursos nacionais e internacionais, muitas vezes com bolsa de estudos, e contavam com financiamentos oficiais para cursos de capacitação de professores, o que aumentava o prestígio do grupo em todo o Brasil.
} 


\section{Atos de Pesquisa em Educação - ISSN 1809-0354 \\ Blumenau, v. 12, n.2, p.425-445, mai./ago. 2017 \\ DOI: http://dx.doi.org/10.7867/1809-0354.2017v12n2p425-445}

abordagem do conceito, apoia ainda em sua proposta veiculada no livro As seis etapas do processo de ensino aprendizagem (DIENES, 1969).

Essa nova abordagem exige outros métodos, em que a aprendizagem está condicionada a um ensino realizado com um vasto material manipulável em atividades investigativas, em situações que retratem concretamente as estruturas e com professores que compreendam o completo significado delas e a maneira como as crianças aprendem.

Dessa maneira, é necessário que o ensino de Aritmética se adapte, etapa por etapa, ao desenvolvimento das estruturas mentais, em cada fase do desenvolvimento da criança. Assim, o destaque nas séries iniciais volta-se para ações que explorem as estruturas lógicas elementares, oferecendo situações em que são construídas estruturas lógicas simples, de modo que a criança possa construir novas e mais complexas estruturas, sem as quais não há possibilidade de construção de conceitos matemáticos elementares, nem ação sobre as operações aritméticas.

Quando aqui se considera que o poder16 tem implicações na dinâmica de aceitação da representação 17 de como ensinar Matemática adequadamente, é necessário lembrar que esta se organiza e se desenvolve, de acordo com interesses de grupos sociais, no nosso caso, os participantes do MMM. Sobre isso, Chartier (1991) lembra que a realidade social, para existir concretamente, precisa ser significada, cabendo às representações sociais o papel de dar sentidos às práticas.

\footnotetext{
${ }^{16}$ Os conceitos de "estratégia" e de "tática", concebidos por Certeau (2011), contribuem para compreender as relações de poder, aquelas relações nada pacíficas imbricadas em uma cultura escolar. Em face às "estratégias" aplicadas pelo sistema detentor do poder, os professores desenvolvem "táticas" de sobrevivência, uma espécie de consumo criativo das normas advindas dos lugares de poder, que se revela em resistência.

${ }_{17}$ Chartier (1991, p. 16) define o conceito de representação como: [...] toda a tradução e interpretação mental de uma realidade exterior percebida. [...], as representações coletivas constroem o próprio mundo social: [...] construções que os grupos fazem sobre suas práticas e que não existem práticas que não seja representada. [...] A história cultural, tal como a entendeu, tem por principal objeto identificar o modo como em diferentes lugares e momentos uma determinada realidade social é construída, pensada, dada a ler. Uma tarefa deste tipo supõe vários caminhos. O primeiro diz respeito às classificações, divisões e delimitações que organizam a apreensão do mundo social como categorias fundamentais de percepção e de apreciação do real. Variáveis consoantes às classes sociais ou os meios intelectuais são produzidos pelas disposições estáveis e partilhados, próprios do grupo. São estes esquemas intelectuais incorporados que criam as figuras graças às quais o presente pode adquirir sentido, o outro tornar-se inteligível e o espaço ser decifrado.
} 


\section{Atos de Pesquisa em Educação - ISSN 1809-0354 \\ Blumenau, v. 12, n.2, p.425-445, mai./ago. 2017 \\ DOI: http://dx.doi.org/10.7867/1809-0354.2017v12n2p425-445}

É papel das representações, por exemplo, fazer desaparecer os interesses específicos pelo recurso à universalização dos propósitos inscritos em toda e qualquer prática social. Logo, a leitura que Dienes faz do passado, produzindo uma representação de "ensino antigo", compõe um contexto de sustentação, de forma a legitimar e implementar suas propostas. Segundo Dienes (1967a, p.15):

\footnotetext{
A compreensão deficiente da estrutura matemática impossibilita a criança de aprender o abstrato. [...] Os estudos contemporâneos mostram que o ensino tradicional não atende à situação atual. [...] No máximo tornam-se destros técnicos na arte de manipular complicados conjuntos de símbolos; na pior hipótese, elas ficam confusas com situações impossíveis em que as atuais exigências matemáticas na escola tendem a colocá-las.
}

É orientado que as primeiras experiências na escola explorem discussões sobre o que é conjunto, conversando sobre os conjuntos da casa, da escola, do mundo físico. Em seguida, é necessário fixar apenas uma palavra que designe uma coleção de objetos, com idêntica propriedade. "Pensamos primeiro na propriedade, depois nas operações com os objetos que as possui" (DIENES, 1969, p. 2).

Guardadas as devidas cautelas, podemos dizer que as propostas de Dienes surgem preenchendo a lacuna de modelos de atividades, operacionalizando a abordagem estruturalista da Matemática, para um "aluno piagetiano". Dienes propõe atividades manipulativas, que, conforme sua representação de aprendizagem matemática, contribuem para a construção das noções elementares.

O autor sugere uma sequência rígida: são introduzidos os conceitos de conjunto, pertinência, subconjuntos e operações com conjuntos, que, didaticamente, facilitam a abordagem de estruturas básicas para a compreensão do conceito de número. Trata-se de atividades que procuram desafiar as crianças a observar, perceber e descrever atributos dos objetos, a fim de estabelecer relação de semelhança e diferença entre eles, estimular a formação de classes pela discriminação e generalização das características observadas.

Ressaltamos que, na perspectiva de Dienes, a sequência de introdução dos novos conteúdos é rígida e controlada. Dessa forma, seguindo as recomendações do autor para a aprendizagem de sucesso, as atividades exploram o estabelecimento de correspondência entre elementos de dois conjuntos. Portanto, 


\section{Atos de Pesquisa em Educação - ISSN 1809-0354 \\ Blumenau, v. 12, n.2, p.425-445, mai./ago. 2017 \\ DOI: http://dx.doi.org/10.7867/1809-0354.2017v12n2p425-445}

nessa etapa, é aconselhável a prática de jogos em que as crianças estabeleçam correspondências entre conjuntos e que consigam discriminar quais são bijeções.

Da forma como foi exposto, as atividades enfatizam vários tipos de representação, contudo, não aparece a representação de quantidades utilizando algarismos indo-arábicos. O autor aconselha que antes da representação convencional, para o sistema de numeração decimal, as crianças explorem muitas outras maneiras de representar quantidades.

Outro aspecto importante nos princípios de Dienes refere-se ao que entende por processo de abstração. Um deles, por exemplo, consiste em reconhecer alguma propriedade comum de uma variedade de situações diferentes. Tal propriedade torna-se um "atributo" de definição de classe recém-formada dos quais as diferentes situações são os elementos. Nesse sentido, Dienes acreditada que o ato de abstração não deve ser confundido com um ato de simbolização ou até mesmo com um ato de manipulação de certos símbolos (SOARES, 2014).

A abstração e a generalização, mesmo que ocorrendo quase que simultaneamente, são considerados dois processos mentais diferentes. Para o autor, a primeira era entendida como a formação de uma classe, uma atividade construtiva e a segunda, a extensão de uma classe, um processo lógico ou analítico. Desta forma, Dienes almejava uma forma eficiente de aprendizagem da matemática.

Assim, as novas práticas metodológicas da década de 1960 de Dienes pregavam que as crianças poderiam compreender, desde cedo, muitos dos importantes conceitos da matemática por meio de experiências voltadas a manipulação de objetos concretos e a produção de materiais didáticos apropriados, além de jogos. Desta forma os alunos teriam um maior sucesso na compreensão da matemática e um maior envolvimento na aprendizagem.

O próprio Dienes alerta para "o perigo da utilização de um único material estruturado que pode criar bloqueios na transferência da aprendizagem realizada, como o perigo de a matemática apreendida ligar-se inteiramente ao material utilizado" (SOARES, 2014, p.52).

Dienes entende por Matemática: 
número (Matemática Pura), ao mesmo tempo em que suas aplicações a problemas tais como são postos na realidade (Matemática aplicada). Por aprendizado de matemática, devo entender a apreensão de tais conexões, bem como de suas simbolizações, e a aquisição da capacidade de aplicar os conceitos formados a situações reais que ocorrem no mundo (DIENES, 1967a, p.30)

Por exemplo, o número aplicado à linha faz surgir o conceito aplicado de medida linear; aplicado à superfície dá origem ao conceito de área, e assim por diante (SOARES, 2014).

$\mathrm{O}$ autor definiu os conceitos de variabilidade perspectiva e matemática. No caso da variabilidade perspectiva, refere-se a uma classificação ligada a percepção, por exemplo: quando usamos diferentes materiais, para classificação. Quanto à variabilidade matemática é ligada a estrutura. Quando trabalhamos a aritmética em diferentes bases, utilizamos a variabilidade matemática, pois estão ligadas as estruturas matemáticas (FRANÇA, 2012, p.182).

\section{AS SEIS ETAPAS DO PROCESSO DE ENSINO E APRENDIZAGEM}

A teoria da aprendizagem de Dienes envolve seis etapas de desenvolvimento. Baseiam-se nas ideias de Piaget sobre o desenvolvimento das estruturas lógicas matemáticas, que dependem da alimentação, complementação e ampliação por meio de atividades previamente planejadas. Na medida em que considera a aprendizagem como um processo de adaptação do indivíduo a um meio, condiciona o sucesso da aprendizagem ao poder de "um determinado meio", em gerar situações que exijam do sujeito adaptações para dominar as situações surgidas. Podemos resumir as seis etapas do processo de aprendizagem, no quadro 1.

Como observamos no quadro denomina a primeira etapa do processo de aprendizagem matemática de "jogo livre", cujo objetivo é propiciar oportunidades em que as crianças, ao manusearem um material concreto, adaptem-se a uma nova situação proposta. A fase se resume basicamente em uma atividade lúdica, em que a criança interage com o ambiente. Esta adaptação do sujeito ao meio, segundo Dienes (1969, p.2) ocorre durante toda a vida. 
Atos de Pesquisa em Educação - ISSN 1809-0354

Blumenau, v. 12, n.2, p.425-445, mai./ago. 2017

DOI: http://dx.doi.org/10.7867/1809-0354.2017v12n2p425-445

\begin{tabular}{|c|c|c|c|c|c|}
\hline $1^{a}$ Etapa & $2^{\mathrm{a}}$ Etapa & $3^{a}$ Etapa & $4^{a}$ Etapa & $5^{\mathrm{a}}$ Etapa & $6^{a}$ Etapa \\
\hline Jogo Livre & $\begin{array}{l}\text { Jogo com } \\
\text { Regras }\end{array}$ & $\begin{array}{l}\text { Jogo do } \\
\text { Isomorfismo }\end{array}$ & Representação & $\begin{array}{l}\text { Descrição de } \\
\text { uma } \\
\text { representação }\end{array}$ & Axiomatização \\
\hline $\begin{array}{l}\text { Exploração } \\
\text { livre, } \\
\text { manipulaçã } \\
\text { o; } \\
\text { Percepção } \\
\text { de } \\
\text { característic } \\
\text { as físicas; } \\
\text { Aquisição } \\
\text { de } \\
\text { vocabulário; } \\
\text { Uso dos } \\
\text { sentidos, } \\
\text { etc. }\end{array}$ & $\begin{array}{l}\text { Percepção } \\
\text { de } \\
\text { restrições; } \\
\text { Adaptação } \\
\text { à nova } \\
\text { situação; } \\
\text { Verbalizaçã } \\
\text { o }\end{array}$ & $\begin{array}{l}\text { Percepção de } \\
\text { propriedades } \\
\text { comuns entre } \\
\text { regras; } \\
\text { Relações de } \\
\text { natureza } \\
\text { abstrata } \\
\text { existentes } \\
\text { entre jogos; } \\
\text { Comparação }\end{array}$ & $\begin{array}{l}\text { Representação } \\
\text { da estrutura } \\
\text { comum em } \\
\text { diferentes } \\
\text { registros, de } \\
\text { forma mais } \\
\text { organizada e } \\
\text { inteligível; } \\
\text { Busca de uma } \\
\text { representação } \\
\text { gráfica para a } \\
\text { estrutura }\end{array}$ & $\begin{array}{l}\text { Descrição de } \\
\text { uma } \\
\text { representação; } \\
\text { Exploração } \\
\text { das } \\
\text { propriedades } \\
\text { das } \\
\text { representaçõe } \\
\text { s construídas e } \\
\text { das } \\
\text { abstrações; } \\
\text { Busca por } \\
\text { tradução da } \\
\text { representação } \\
\text { simbólica }\end{array}$ & $\begin{array}{l}\text { Sistema formal, } \\
\text { método, } \\
\text { organização de } \\
\text { algumas } \\
\text { propriedades, } \\
\text { axiomas, } \\
\text { teoremas e } \\
\text { provas }\end{array}$ \\
\hline
\end{tabular}

Fonte: (FRANÇA, 2012, p.102)

$\mathrm{Na}$ etapa seguinte, são ditadas regras pelo professor, conforme o conceito matemático a ser desenvolvido. O desafio maior é a adaptação possível, combinar e construir novas estruturas, a fim de dominar as novas situações, utilizando as estruturas já formadas, as regularidades descobertas e as limitações do meio.

$\mathrm{Na}$ terceira etapa, percebe-se a estrutura comum dos jogos estruturados já efetuados, descobrindo as relações de natureza abstrata existentes entre os elementos de um e de outro jogo, o que precede à abstração do conceito.

$\mathrm{Na}$ quarta etapa, chamada "representação", a proposta é representar a estrutura comum, em diferentes registros, a fim de mais tarde poder examinar.

"Descrição de uma representação" é a quinta etapa, identificada por Dienes, na qual explora-se e descreve-se as propriedades comuns das representações construídas, das abstrações.

Dada a impossibilidade de descrever completamente as propriedades, por meio da linguagem, há a sexta etapa, fruto de todas as anteriores, denominada "axiomatização", em que se organizam sistematicamente algumas propriedades dos sistemas formais criados.

Segundo Dienes (1969, p.67):

[...] na pedagogia tradicional, trabalha-se exatamente em sentido contrário. Introduz-se um sistema formal, por meio de símbolos. Percebe-se que a 
criança não está apta a compreender tal sistema e por isso se lança mão de meios audiovisuais para fazê-la compreender. Isto quer dizer que, a partir da etapa do simbolismo, passa-se à etapa da representação. Descobre-se ainda, que a criança não está apta a aplicar os conceitos, mesmo depois dos recursos audiovisuais; consequentemente torna-se necessário ensinar-Ihe as aplicações na realidade. Chega-se, finalmente, à realidade, de onde se deveria ter partido. Assim, no ensino tradicional, a direção da aprendizagem é exatamente contrária à proposta nestas páginas.

\section{DIENES NA REVISTA DE ENSINO/RS}

O primeiro artigo analisado de autoria de Grossi foi publicado em agosto de 1973, pela Revista de ensino do RS. Nele, a presidente do GEEMPA relata as atividades de Dienes durante sua estadia no Brasil, em que ministrou curso para professores dos mais diversos pontos do Estado e do país e uma experiência com classes-piloto. Ressalta que isso foi possível graças a uma iniciativa pioneira do Grupo de Estudos sobre o Ensino da Matemática de Porto Alegre (GEEMPA).

Segundo Grossi (1973, p.45),

[...] durante 17 dias em que esteve em Porto Alegre, o Prof. Dienes trabalhou todas as manhãs com um grupo restrito de professores (50), estudando a abordagem de novos conteúdos na escola primária, naturalmente com uma metodologia completamente renovada e, à tarde, na presença de 1.000 professores, orientou aulas-demonstração com alunos desde 6 até 15 anos.

O que soa quase que surreal para os dias atuais, ocorreu nesse curso, "durante 40 horas-aula, o professor não se preocupou em ensinar matemática aos 1.000 professores participantes do curso [...] mas preocupou-se e demonstrar como é possível ensinar Matemática às crianças", destaca (POÇAS; ATHANÁSIO, 1972, p.9) em outro artigo analisado.

O referido curso foi realizado em um ginásio de esportes, dividido em três etapas. No primeiro momento Dienes explicou as regras dos jogos aos professores; em seguida informou a regras as crianças que ficavam no centro do ginásio experimentando, além de acompanhar de perto o que estavam realizando; finalmente, descreveu à plateia as conclusões a que as crianças tinham chegado e quais conteúdos matemáticos poderiam relacionar com cada jogo.

Conforme visto na seção anterior, Dienes teoriza sobre as seis etapas do 
processo de ensino e aprendizagem. Contudo, no curso em Porto Alegre foram desenvolvidas as quatro primeiras, visto que as duas últimas necessitavam de estruturas elementares impróprias para a faixa etária do curso, segundo Dienes.

$\mathrm{Na}$ figura 1, a foto publicada na revista de ensino (POÇAS; ATHANÁSIO, 1972, p.8), mostra um momento dessa experiência.

Figura 1 - Professor Dienes mostra como se trabalha com matemática viva

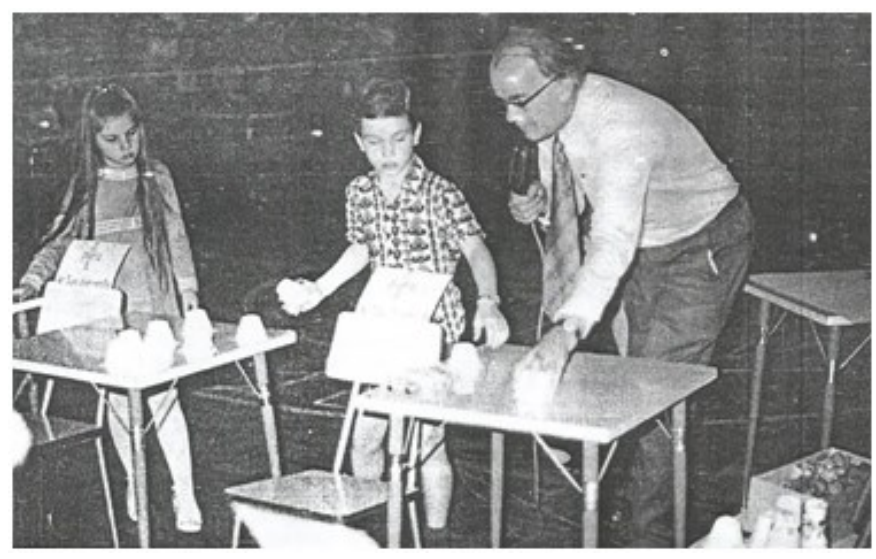

Fonte: (POÇAS; ATHANÁSIO, 1972, p.8).

A foto pode indicar à ênfase dada por Dienes à metodologia, com a introdução de materiais manipuláveis para a realização das atividades, predominantemente em trabalho em grupo. Podemos dizer que Dienes levou para as salas de aula blocos lógicos ${ }^{18}$, material multi base ${ }^{19}$ e o material dourado ${ }^{20}$, visto que as atividades são propostas para serem realizadas com a utilização desses instrumentos de maneira ativa, viva.

Um exemplo de bloco multibase 4 pode ser observado na figura 2. Para Dienes a criança deveria passar por várias caixas: base 3, 4, 5, 6 e 10. Desta forma: "é preciso praticar nessas trocas durante muito tempo, até que as equivalências

\footnotetext{
${ }^{18} \mathrm{Um}$ jogo de blocos lógicos é um conjunto constituído de 48 peças, que apresenta os seguintes atributos: cor (vermelho, azul e amarelo), tamanho (grande e pequeno), forma (quadrado, retângulo, triângulo e círculo) e espessura (fino e grosso). Soares (2014) afirma que Dienes baseou este jogo nos blocos de atributos de Willian Hull.

${ }^{19} \mathrm{O}$ material é constituído de peças de madeira de formas geométricas de duas e três dimensões. Quando manipuladas, evidenciam as etapas de construção do sistema de numeração em diferentes bases.

${ }^{20}$ Confeccionado em madeira, é composto por cubos, placas, barras e cubinhos. O cubo é formado por dez placas; a placa por dez barras; e a barra por dez cubinhos. Destinado a representar os números em forma geométrica.
} 
pareçam naturais aos alunos" (DIENES, 1967b, p.85).

Sugere ainda, as trocas de dinheiro ou figurações, tais como fichas coloridas. Um exemplo na base 5 poderia ser 5 fichas vermelhas valem 1 verde; 5 verdes valem uma rosa, 5 rosas valem uma branca e assim por diante. Ou seja, todas essas trocas conduzem à criança à descoberta da noção de 'valor de poisção, ou 'posicional' (SOARES, 2014).

Figura 2 - Material Multibase - base 4

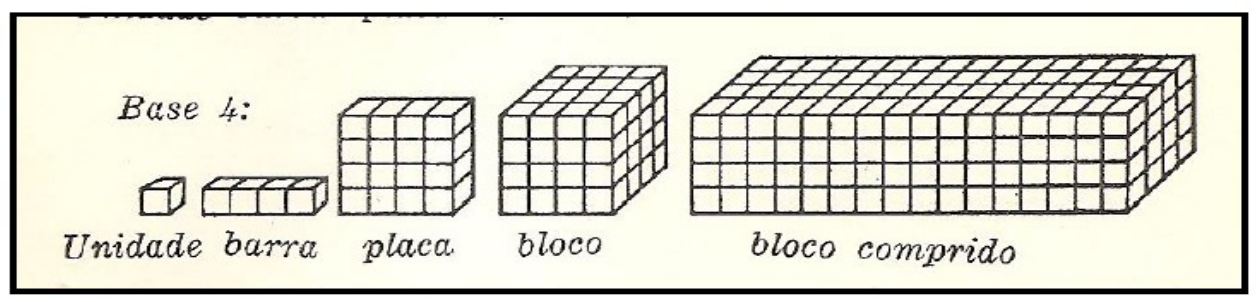

Fonte: DIENES, 1967b, p.107.

No artigo de Poças e Athanásio (1972, p.8) podemos observar a representação dos autores sobre as ideias defendidas por Dienes: "método da matemática viva" apregoa que "o aluno é agente e segue os caminhos do raciocínio" recebendo "objetos que o conduzem à busca de soluções para os problemas que Ihes são propostos" por meio de "plaquetas coloridas, sólidos desmontáveis, de diversas dimensões, o aluno busca soluções para as situações propostas pelo professor". "O professor mantém-se como "coordenador", sem impor a solução do problema, sem sobrecarregar o aluno a cada momento e apenas sugerindo, através de símbolos e objetos as pesquisas" (POÇAS E ATHANÁSIO, 1972, p.9). Essa citação corrobora com as ideias de Dienes, visto que as propostas de atividades descritas acima são colocadas sem comandos, regras ou restrições; são desafiadoras e provocam uma ação, isto é, brincar livremente com o material, conversar, tatear e, muitas vezes, construir formas que retratam o dia a dia (carrinhos, bonecos, etc.).

Conforme visto na seção anterior, Dienes teoriza sobre as seis etapas do processo de ensino e aprendizagem. Contudo no referido curso foram desenvolvidas as quatro primeiras. Poças e Athanásio (1972, p.9) descrevem que: 
Inicialmente, a criança brincava livremente, familiarizando-se com o material, através de manipulação; a seguir, recebia as regras, as restrições do jogo, sendo levada a constatar a existência de bloqueios que deveriam ser superados, pela busca de soluções. Numa terceira etapa, estabelecia comparações entre os jogos estruturados e, numa última etapa, fazia a representação da situação obtida através da comparação (fase de abstração).

Poças e Athanasio (1972) aludem em seu artigo que "a criança aprende matemática não por ter chegado à resposta certa, mas porque foi capaz de procurar solução para o problema" (p.9). Reforçam a ideia trazendo uma entrevista Dienes publicada na Revista de Ensino, em que argumenta que uma das grandes falhas da matemática tradicional seria o problema da "resposta certa" em que os professores restringem-se a um conjunto de "truques" que em sua maioria não eram entendidas nem pelos professores e nem pelas crianças.

[...] isso se dava devido à falta de domínio da matéria pelos professores, que não podiam se afastar das respostas contidas nos manuais. Assim, quando as crianças chegavam a soluções originais, eram desencorajadas pelo professor, porque estas não constavam nos manuais e não havia como saber se estavam ou não corretas. (POÇAS E ATHANASIO, 1972, p.9).

Já em 1972, Dienes apontava como raízes desse problema o fato dos matemáticos desconhecerem os problemas psicopedagógicos e os pedagogos e psicólogos não entenderem de matemática, ou seja, o diálogo era muito difícil. $\mathrm{O}$ ideal seria que o professor tivesse o conhecimento dessas três áreas e "só assim poderia dar as crianças a liberdade de que elas necessitam" (POÇAS, ATHANASIO, 1972, p.9).

Na entrevista concedida a revista, Dienes enfatizou ainda que:

[...] a Matemática está entrosada com todas as demais ciências, mas que para integrá-la a elas, o melhor meio será enriquecer a aula de Matemática com toda a sorte de material concreto. Incluem-se aí o material estruturado e o material não estruturado, como a areia, a água, os animais, as plantas, os fenômenos naturais, enfim, tudo o que a criança possa observar (POÇAS E ATHANASIO, 1972, p. 10).

No artigo de Grossi (1973), além de reportar a vinda de Dienes a Porto Alegre em 1972, descreve a experiência baseada na metodologia renovada com oito classes-piloto em seis escolas de Porto Alegre.

As escolas selecionadas foram aquelas "que tinham um bom número de 


\section{Atos de Pesquisa em Educação - ISSN 1809-0354 \\ Blumenau, v. 12, n.2, p.425-445, mai./ago. 2017 \\ DOI: http://dx.doi.org/10.7867/1809-0354.2017v12n2p425-445}

professores com curso de atualização em Matemática" (GROSSI, 1973, p.45) e as bases do trabalho foram duas: "1) A liberdade é fator de motivação. 2) O aluno só abstrai a partir do concreto" (GROSSI, 1973, p.45).

Nessa perspectiva, os alunos na faixa etária de 6 a 12 anos, entre a primeira e sexta séries do ensino fundamental de 8 anos, geralmente trabalhavam em pequenos grupos com liberdade para escolher a sua tarefa escolar pois os professores punham a sua disposição muitos materiais didáticos concretos e fichas de trabalho indicando as regras da atividade.

A experiência teve a duração de três meses. Segundo Grossi (1973) "não houve preocupação de modificar o conteúdo matemático que já era atualizado nas seis escolas escolhidas" (p.45). O que teria maior alteração seria a didática "pois o uso de muitos materiais didáticos concretos para trabalho livre dos alunos tinha como objetivo seguir as seis etapas do processo de aprendizagem em matemática segundo Piaget-Dienes" (p.45).

O desejo era que "os alunos fizessem suas descobertas a partir de problemas propostos nos jogos estruturados em forma de regras" (GROSSI, 1973, p.46). Acrescenta que ao final dos três meses os alunos das turmas experimentais "apresentavam grande diferença dos seus colegas das outras turmas das mesmas séries na sua escola" (p.46).

Grossi (1973) relata que os professores encontravam-se semanalmente durante quatro horas de estudo, para revisão e planejamento do trabalho em classe. Integravam esta equipe uma psicóloga e uma professora de ciências naturais. Cada classe possuía uma observadora que uma vez por semana visitava a sala de aula e que também participava das reuniões. Para garantir um trabalho escolar diversificado cada aluno possuía uma de registro ou "ficha-controle" que permitia ao professor "planejar o progresso de cada aluno através da confecção de novos materiais, assim como da elaboração de novas fichas de trabalho" (GROSSI, 1973, p.46).

A fala de Grossi (1973) reforça uma característica marcante de Dienes na ênfase dada às contribuições da Psicologia e Pedagogia nas suas propostas. Afirma que qualquer proposta de ensino de Matemática deve nortear-se por princípios psicológicos e pedagógicos com o cuidado na elaboração de atividades bem planejadas pelo professor, de acordo com os objetivos a serem alcançados pelo 


\section{Atos de Pesquisa em Educação - ISSN 1809-0354 \\ Blumenau, v. 12, n.2, p.425-445, mai./ago. 2017 \\ DOI: http://dx.doi.org/10.7867/1809-0354.2017v12n2p425-445}

professor.

Para elucidar a experiência, Grossi (1973) relata o trabalho realizado com a primeira série. Os conteúdos classes de equivalência, número cardinal e ordem dos números

[...] foram manipulados na forma de jogos, com os seguintes materiais didáticos concretos: - Blocos lógicos - Conjuntos de autinhos, aviõezinhos, panelinhas, de brinquedo, estruturados segundo cor, tamanho, forma etc. Bolas de diversos tamanhos e cores, que se encaixavam - Fitas com casas e botões - Conjuntos de conjuntos com três atributos cada um com dois valores

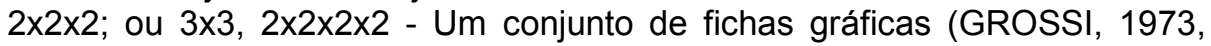
p.47).

Em relação as fichas gráficas, afirma que muitas "foram utilizadas neste momento, sob a inspiração dos livros de Mme. Picard, M. Dienes, Mme. Papy e Mme. Clausard" (GROSSI, 1973), autores referência para as séries iniciais da época.

Para Grossi (1973), corroborando com Dienes, a "aprendizagem real" da matemática

[...] só se fará se o aluno dispuser de muito material didático, planejado e construído para a aprendizagem de cada conceito e, com ele, jogar numa atividade agradável. Aprender algo é imensa fonte de prazer. Eles gostarão de freqüentar a escola, não só pelo aspecto social de estar entre companheiros da mesma idade, mas pela própria atividade discente (GROSSI, 1973, p.53).

Aponta como principais obstáculos encontrados nas classes-piloto a dificuldade de mudança, o receio de o professor perder o domínio da turma ensinando a matemática nos novos moldes, necessidade de preparar certa quantidade de materiais concretos que demandam tempo, necessidade que o professor estude mais, pois o êxito de sua atividade docente está no seu preparo. Ou seja, é necessário que o professor trabalhe mais antes de cada aula preparando materiais, fichas e analisando a ficha-controle detalhadamente (GROSSI, 1973, p.53). Complementa que "para realizar uma reforma, não basta só a boa vontade do professor" (p.53), sendo preciso apoio mútuo, o que aconteceu nas classes-piloto "onde havia reuniões semanais, observadores e assessores" (p.53).

No início, os professores tiveram muita dificuldade e sentiram-se perdidos. Entretanto, 
[...] no final da experiência, estes mesmos professores afirmavam não conceberem trabalhar mais de outro modo, pois, após o primeiro impacto de orientar uma classe com atividades diferenciais, o que é difícil, o professor começa a se desgastar menos, porque os alunos se tornam mais independentes, tomam gosto pelos jogos, se relacionam melhor com os colegas. Os nossos professores apalparam as vantagens, sentiram os alunos aprendendo verdadeiramente, pesquisando com ela, <quebrando a cabeça> com interesse, concentrando-se nos jogos durante um tempo muitíssimo superior ao que podia ocupar os alunos com os exercícios tradicionais de matemática (GROSSI, 1973, p.53).

Fazendo um balanço dos três meses de aplicação da teoria baseada em jogos de Dienes nas classes-piloto Grossi (1973) conclui que "proporcionaram, num clima de liberdade, maior criatividade, maior socialização, maior responsabilidade, simultaneamente com um rendimento de aprendizagem muitíssimo superior, contatado claramente pela comparação com as classes controle" (p.53).

Percebemos no artigo de Grossi (1973) que havia ênfase no uso do material concreto, pois nesse período estavam mergulhados na representação de que a aprendizagem do aluno dependia do método de ensino e do material empregado.

Outro artigo que merece destaque é Operações Matemáticas no $1^{\circ}$ ano, publicada em novembro de 1972 na Revista de Ensino/RS e da autoria de Léa da Cruz Fagundes que exemplifica apropriações das ideais de Piaget, Dienes e as relações com o MMM.

\begin{abstract}
"Professora, afinal, quando é que meu filho vai começar a 'fazer continhas? Já estamos em junho!" Vamos tentar uma primeira explicação. Ensinar a 'fazer continhas' (automatizar os algarismos das operações) é a fase final de um processo, não o seu início, quando queremos desenvolver estruturas operatórias de inteligência e evitar que a criança copie um modelo, passando a repeti-lo sem elaboração pessoal. Se um aluno nos perguntar: "Esse problema é de mais ou é de menos?" de que lhe serviu ter aprendido a fazer adições e subtrações? Isso nos leva a indagar se terá ele realmente construído algum conceito de operação! Nossa decisão é, por isso, identificar os pré-requisitos para a programação sequencial do ensino e determinar as melhores condições para a organização das experiências de aprendizagem, baseando-nos, na teoria psicogenética de Jean Piaget, em Dienes, em Licheranowicz, em Bruner, de um lado, e nas estruturas fundamentais da Matemática, determinadas pelos matemáticos Bourbaki, de outro lado (FAGUNDES, 1972, p.23).
\end{abstract}

Fagundes (1972) segue definindo operação e aprendizagem das operações matemáticas na perspectiva de Jean Piaget, ou seja, acredita que essas noções ocorrem muito antes de aprender a somar e diminuir números. Considerando a 


\section{Atos de Pesquisa em Educação - ISSN 1809-0354 \\ Blumenau, v. 12, n.2, p.425-445, mai./ago. 2017 \\ DOI: http://dx.doi.org/10.7867/1809-0354.2017v12n2p425-445}

operação como a "mudança de um estado determinado para um novo estado, a possibilidade de voltar ao estado inicial" (FAGUNDES, 1972, p.23), quando uma criança de 10 a 12 meses desloca, por exemplo, um "caminhãozinho, um chocalho, uma almofada, qualquer objeto, de um ponto $A$ para um ponto $B$, realiza uma transformação de estado" (p.23) e chama a atenção que este exemplo propicia à iniciação da criança as duas formas de reversibilidade (negação/inversão e reciprocidade/compensação) "as quais encontraremos lado a lado durante todo o desenvolvimento da inteligência e que só serão sintetizadas num único sistema ao nível das operações formais depois do 11-12 anos" (p.24).

Para ajudar a criança na passagem da ação à operação "concreta" do pensamento Fagundes (1972, p.24) diz que é oportuno

[...] organizar um ambiente rico e propiciar, entre outras, atividades exploratórias, que ajudem a corrigir as percepções parciais e momentâneas, os esquemas operatórios incompletos, e construir as noções de conservação das substâncias, dos comprimentos, das superfícies, das quantidades, em conjuntos contínuos e discretos, aproveitando o momento ótimo de cada indivíduo, favorecendo a estruturação mental para novos estágios (FAGUNDES, 1972, p.24).

Na análise do artigo verificamos que Fagundes (1972), corrobora com Dienes quando este argumenta que sendo "o número um conceito muito complexo, para aprender a harmonizar entre si os elementos conceituais que os constituem, é indispensável, antes de tudo, conhecer estes elementos” (DIENES, 1967c, p. 1).

Outro exemplo de apropriação é o artigo de Lopes (1973) "Pesquisa com estrutura de grupo" em que explora "algumas sugestões do professor Dienes para a pesquisa de estrutura de grupo" (LOPES, 1973, p.12), utilizando os conceitos de transformação, composição de transformações e grupo. Na contextualização da fala da professora percebemos as ideias de Dienes

\footnotetext{
O ensino das Ciências seria bem mais eficiente se, para chegarmos às abstrações, partíssemos sempre de situações problemáticas do Mundo em que vivemos. As Ciências, assim tratadas, se tornam algo vivo e dinâmico. Por esse caminho podemos atingir os mais altos níveis de abstrações, mas não devemos esquecer a última etapa da aprendizagem, que é verificar a aplicabilidade do que se aprendeu no nosso Mundo. Sem completar esse ciclo, será em vão todo o esforço que se fizer no sentido de melhorar o ensino das Ciências (LOPES, 1973, p.12).
}

Em sintonia com as ideias do MMM, após dar vários exemplos de operações 
de transformações sobre conjuntos, finaliza o artigo sintetizando que "as estruturas de ordem, algébricas, cujo protótipo é o grupo, e topológicas são as estruturas fundamentais sobre as quais deve apoiar-se o ensino de $1^{\circ}$ grau" (LOPES, 1973, p.14).

Lembramos que uma característica marcante de Dienes é a ênfase dada às contribuições da Psicologia e Pedagogia nas suas propostas. Nos artigos analisados há sinais marcantes dos princípios que norteiam a proposta de Dienes, que revelam uma representação de ensino e aprendizagem atrelada à Matemática, Psicologia e Pedagogia e a fundamentalmente cognitivista, apoiada, de maneira explícita, na Epistemologia Genética de Piaget.

\section{CONSIDERAÇÕES FINAIS}

Nas Revistas analisadas podemos perceber que os autores se apropriaram das ideias de Dienes que em grande medida dialogavam com a vaga pedagógica da escola nova, porém entendendo a matemática como uma estrutura como os modernistas apregoavam.

Um dos componentes que revela apropriações das ideias de Dienes e MMM pelos autores dos artigos analisados, no ensino nas séries iniciais é a presença explícita das orientações de como ensinar, postas por ele na fundamentação da metodologia proposta pelo MMM.

O estudo também revela o pioneirismo de um grupo de professores do Rio Grande do Sul (GEEMPA) na apropriação e circulação das ideias de Dienes, visto as experiências em classes piloto das séries iniciais promovidas pelo grupo.

No entrecruzamento das informações contidas nos artigos é evidenciada inicialmente a dificuldade dos professores de assumirem a nova proposta. Talvez pela insegurança nos conteúdos. Contudo, Grossi considerou o resultado favorável já que os professores perceberam a mudança na aprendizagem de seus alunos em relação às turmas controle. Outro fator preponderante foi o suporte dado aos professores pelo grupo GEEMPA por meio de reuniões semanais para discussão e elaboração das atividades propostas aos alunos de acordo com os objetivos desejados.

Lembramos que uma característica marcante de Dienes é a ênfase dada às 
contribuições da Psicologia e Pedagogia nas suas propostas. Nos artigos analisados há sinais marcantes dos princípios que norteiam a proposta de Dienes, que revelam uma representação de ensino e aprendizagem atrelada à Matemática, Pedagogia e a Psicologia fundamentalmente cognitivista, apoiada, de maneira explícita, na Epistemologia Genética de Piaget.

Em síntese, as revistas fazem circular a ideia que não se pode ensinar matemática sem o auxílio da psicologia e pedagogia, sempre observando o nível de complexidade a ser utilizado pelas crianças nas atividades propostas, ou seja, há uma valorização dos saberes para ensinar. Traz inovações para a didática dessa área do conhecimento, quando propõe concretizações de conceitos matemáticos abstratos, a partir de manipulações de materiais estruturados em jogos, brincadeiras, histórias, etc. Assim como as novas propostas da escola totalmente baseada em jogos, de hoje.

\section{BARBARA WINIARSKI DIESEL NOVAES}

Doutora em Educação pela Pontifícia Universidade Católica do Paraná - PUCPR Professora da Universidade Tecnológica Federal do Paraná - UTFPR - Câmpus Toledo.

\section{DENISE MEDINA DE ALMEIDA FRANÇA}

Doutora em Educação pela Universidade de São Paulo. Pesquisadora do GHEMAT - Grupo de Pesquisa de História da Educação Matemática no Brasil.

\section{REFERÊNCIAS}

BRASIL. Lei $\mathrm{n}$ - 4.024, de 20 de dezembro de 1961. Fixa as Diretrizes e Bases da Educação Nacional. Documental, Rio de Janeiro, n. 1, mar. 1962. . Ministério da Educação e Cultura. Lei 5.692, de 11 de agosto de 1971. Lei de Diretrizes e Bases da Educação Nacional, 1971. Disponível em: <http://www.planalto.gov.br/ccivil_03/leis//5692.htm>. Acesso em 6 jun. 2010.

CERTEAU, M. d. A invenção do cotidiano: 1. Artes de fazer; 17. ed. Tradução de Ephraim Ferreira Alves. Petrópolis, RJ: Vozes, 2011. 216p.

CHARTIER, R. O Mundo como representação. Trad. Andréa Daher e Zenir Campos Reis. Estudos Avançados, São Paulo, v. 5, n. 11, p. 173-191, jan./abr. 1991. Disponível em: <http://www.scielo.br/pdf/ea/v5n11/v5n11a10.pdf>. Acesso em: 22 jul. 2012. 


\section{Atos de Pesquisa em Educação - ISSN 1809-0354 \\ Blumenau, v. 12, n.2, p.425-445, mai./ago. 2017 \\ DOI: http://dx.doi.org/10.7867/1809-0354.2017v12n2p425-445}

DIENES, Z. P. Aprendizado moderno da Matemática. Rio de Janeiro: Zahar, 1967a.

, Zoltan Paul. A Matemática Moderna no ensino primário. São Paulo: Editora Fundo de Cultura S/A, 1967b.

, Zoltan Paul. Conjunto, Números e Potências. São Paulo: Herder, 1967c.

, Zoltan Paul. As seis etapas do processo de aprendizagem em matemática. São Paulo: Herder, 1969.

FAGUNDES, L. d. C. Operações matemáticas no $1^{\circ}$ ano. Revista do Ensino, Porto Alegre, n.145, p.23-24, 1972.

FRANÇA, D. M. d. A. Do primário ao primeiro grau: as transformações da Matemática nas orientações das secretarias de educação de São Paulo (1961-1979) e o conceito de número. 2012. 294 f . Tese. (Doutorado em Educação) Universidade do Estado de São Paulo- USP, São Paulo, 2012.

FISCHER, M. C. B. A experiência das classes-piloto organizadas pelo GEEMPA, ao tempo da Matemática Moderna. Revista Diálogo Educacional. Curitiba, Paraná: PUCPR, v.6, n.18, p.101-112, maio/ago, 2006.

GROSSI, E. P. Uma experiência fascinante em aprendizagem de matemática. Revista do Ensino, Porto Alegre, n.150, p.45-53, 1973.

HOFSTETTER, R.; SCHNEUWLY, B. (éds.) Savoirs en (trans) formation - Au coeur des professions de l'enseignement et de la formation. Bruxelles: Éditions De Boeck Université, 2009.

LOPES, L. S.. Pesquisa da estrutura de grupo. Revista do Ensino, Porto Alegre,n.146, p.12-14, 1973.

NOVAES, B. W. D. O Movimento da Matemática Moderna em escolas técnicas industriais do Brasil e de Portugal: impactos na cultura escolar. 2012. 235 f. Tese (Doutorado Educação) - Pontifícia Universidade Católica do Paraná, Curitiba, 2012.

OLIVEIRA, M. C. A. d.; SILVA, M. C. L. d.; VALENTE, W. R. (Orgs.). O Movimento da Matemática Moderna: história de uma revolução curricular. Juiz de Fora: Editora da UFJF, 2011.

PEREIRA, L. H. F. Os discursos sobre a matemática publicados na revista de Ensino do Rio Grande do Sul - (1951-1978). 2010. 315 f. Tese (Doutorado em Educação)Pontifícia Universidade Católica do Rio Grande do Sul, Porto Alegre, 2010.

POÇAS, I. M.; ATHANÁSIO, N. C.. Prof. Dienes mostra como se trabalha com matemática vida. Revista do Ensino, Porto Alegre, n.144, p.8-10, 1972.

PORTELA, M. S. Práticas de Matemática Moderna na formação de normalistas no 


\section{Atos de Pesquisa em Educação - ISSN 1809-0354}

Blumenau, v. 12, n.2, p.425-445, mai./ago. 2017

DOI: http://dx.doi.org/10.7867/1809-0354.2017v12n2p425-445

Instituto de Educação do Paraná na década de 1970. 2010. 137 f. Dissertação de (Mestrado Educação) - Pontifícia Universidade Católica do Paraná, Curitiba, 2010.

ROMANELLI, O. d. O.. História da Educação no Brasil. 3.ed. Rio de Janeiro: Editora Vozes, 1982.

SILVESTRE JR, F. S. Conheça a incrível escola totalmente baseada em jogos. Disponivel em: <https://www.linkedin.com/pulse/conhe\%C3\%A7a-incr\%C3\%ADvelescola-totalmente-baseada-em-jogos-silvestre-jr?trkSplashRedir=true\&forceNoSplash=true> Acesso em: 05 mar. 2016.

SOARES, E. T. P. Zoltan Paul Dienes e o Sistema de Numeração decimal na cultura escolar paranaense (1960-1989). 2014. 288 f. Tese (Doutorado Educação) -

Pontifícia Universidade Católica do Paraná, Curitiba, 2014. 